\title{
The Future of Breeding Vegetables with Human Health Functionality: Realities, Challenges, and Opportunities
}

\author{
Irwin L. Goldman ${ }^{1}$ \\ Department of Horticulture, University of Wisconsin-Madison, 1575 Linden Drive, Madison, WI 53706
}

Additional index words. functional food, nutrition, phytochemicals, plant breeding

\begin{abstract}
Crops have been important to humankind for purposes other than simply sustaining life through calories and nutrients. Many of the earliest domesticates served multiple purposes besides food (Meyer et al., 2012), including providing for shelter, textile, medicinal, or spiritual needs. In some cases, medicinal uses may have preceded their use as food crops (Rubatzky and Yamaguchi, 1997; Smartt and Simmonds, 1995). However, during the latter half of the 20th century, and particularly in the United States, healthcare practitioners and the general public moved away from food-based remedies and toward synthetic medicine (Lawson, 1998). Synthetic monomolecular drugs became synonymous with modern medicine in many parts of the developed world, leading to tremendous gains in public health. However, the departure from plant-based remedies was accompanied by a loss of knowledge about their uses and efficacy (Goldman, 2003; Janick, 2003).
\end{abstract}

Onion (Allium cepa L.), garlic (Allium sativum L.), and other members of the cultivated Alliaceae are excellent examples of this historical fact, because they have been used to flavor food, as vegetables themselves, and as medicinal plants since their domestication more than 5000 years ago (Block, 2010). Depictions of Egyptians harvesting Alliaceae vegetables in wall paintings exist from antiquity. Use of garlic bulbs in ancient burial practices in Egypt have also been well documented (Block, 2010) because of the widespread belief of the importance of these plants for health and well-being in the afterlife. Numerous representations of onion and garlic in art and culture exist through modern times such as the widespread use of Alliaceae-based poultices in Europe or the appearance of leeks on Welsh coinage. Shortages of onion in India have led to street protests (Nolen, 2011). These examples suggest that vegetable Alliums are important additions to cuisine not only because of the flavor they impart to food, or their inherent qualities as vegetables themselves, but also because of their potential health value. If,

\footnotetext{
Received for publication 30 July 2013. Accepted for publication 20 Sept. 2013.

This paper was part of the colloquium "Advances in Breeding Vegetables and Fruits for Enhanced Nutritional Content" held 31 July 2012 at the ASHS Conference, Miami, FL, and sponsored by the Vegetable Breeding Working Group.

${ }^{1}$ To whom reprint requests should be addressed; e-maililgoldma@wisc.edu.
}

however, humans have imparted such health value to these plants, why then does the modern pharmacy contain primarily synthetic monomolecular pharmaceuticals? Although marketers have promoted fruits, vegetables, grains, nuts, herbs, and other crops as having value-added health characteristics, sufficient confusion and misinformation in this marketplace over the past 20 years have added to the complexity of understanding the role of these commodities in improving human health. More than simply a public relations problem for vegetables, this situation hints at some of the deeper and more complex aspects of the connection between crops and health functionality.

\section{FUNCTIONAL FOODS}

Functional foods have been defined as those foods that deliver health benefits beyond nutrition. The term does not carry legal weight in the United States, but it is often used in marketing efforts (American Dietetics Association, 2009). According to this definition, a food can be made functional by adding ingredients, by increasing the amount of native ingredients, or perhaps by simply noting the health functional ingredients that may already exist. The term has been in existence for more than 20 years, but it has not necessarily improved clarity with respect to matters of food and health. Vegetables may contain health-functional ingredients alongside health-dysfunctional ingredients, but neither of these poles has generally received sufficient study to determine the full spectrum of health-positive and healthnegative ingredients in a particular food. Vegetables that might be naturally healthfunctional such as garlic and onion that have rarely, if ever, been promoted as such by marketers may appear old-fashioned or mundane in comparison with newly fabricated foods of today (Smith and Charter, 2010).

It is also noteworthy that an increasing number of processed foods sold in the modern marketplace contain ingredients or functionalities one would not normally recognize for those foods. Examples include orange juice with added calcium or chocolate milk with added immunity protection. Data have accumulated on some of these food products, indicating where they may have health value for consumers (Andon et al., 1996). Although it is true that Aristotle's phrase "Let your food be your medicine and your medicine be your food" is, in concept, similar to today's trend toward health functionality in food, the degree to which food has become compared with medicine has grown substantially since modern functional foods began to appear. It is also true that the aging population of the United States has perhaps placed unrealistic expectations on food itself, including the nutrients contained therein and the expectation that technological approaches to health functionality can go a long way toward preventing disease. This subject has been explored by Michael Pollan in several popular books, including Omnivore's Dilemma (Pollan, 2006) and In Defense of Food (Pollan, 2008). There is a body of research demonstrating that consumption of fruits, vegetables, and whole grains in the context of a regular diet can contribute to positive health outcomes (Bellavia et al., 2013). The World Health Organization (WHO) has promoted fruit and vegetable intake as a key aspect of reducing the preventable burden of serious disease (WHO, 2004). There is, however, far less research on specific health outcomes such as those for a particular disease and its association with particular nutrients in those foods. Finally, there is an exceedingly small and sparse body of work on the longterm health functionality of individual whole foods in the context of a complex diet.

In certain cases, foods with positive health functionalities such as broccoli (Brassica oleracea), blueberry (Vaccinium spp.), and grape (Vitis vinefera) have been extracted and bottled to simulate the manner in which synthetic medicines normally appear. Supplements manufactured from broccoli, blueberry, and grape have become much more common on today's grocery shelves. Some of these products are promoted prescriptively as medicines and may be viewed from a marketing perspective as "silver bullet" cures for a variety of ailments. Although the scientific literature contains examples of the potential health functionality of these foods and their extracts, most of these studies focus on in vitro experiments that may suggest positive health outcomes but are not necessarily conclusive. Few clinically-relevant findings have been realized to substantiate these claims. A recent study (Charradi et al., 2013) investigated rats fed a high-fat diet that caused kidney damage because of its high level of lipids. Rats on this diet that also received grape seed and grape skin extract at $500 \mathrm{mg} \cdot \mathrm{kg}^{-1}$ of body weight showed a partial reversal of the triglyceride deposits by decreasing oleate deposition by $30 \%$ and stearate depletion by $157 \%$ as well as reduced kidney damage compared with rats not receiving the extracts. The amount of grape seed and grape skin extract consumed by the rats was equivalent 
to $35 \mathrm{~g} \cdot \mathrm{d}^{-1}$, a dose that would be attainable through a nutritional supplement. Although these results may be promising, it would be premature to conclude that such results translate into similar findings in humans.

\section{TARGETED HEALTH CLAIMS}

The pomegranate (Punica granatum) and its promotion as a health value-added product represents an example of how health claims for food crops have been examined by the public, government regulators, and the courts. Similar to onion and garlic, the pomegranate is an ancient food crop that was used in Egypt and depicted in paintings throughout the renaissance for its importance as a food and a symbol of fertility. In recent years, pomegranatesourced products such as juice have increased in visibility in the U.S. market. In 2012, the Federal Trade Commission (FTC) prevailed in its case against California-based POM Wonderful (hereafter POM), a manufacturer and promoter of pomegranate juice products. The FTC alleged, and an administrative law judge similarly ruled, that POM had falsely exaggerated the health benefits of their pomegranate juice products for many years (Villafranco and Pippins, 2013). The primary claims adjudicated were for heart disease, prostate cancer, and erectile dysfunction. POM appealed the administrative law judge's ruling, and the FTC struck down the appeal in Jan. 2013.

POM's advertisements were often provocative in their claims that pomegranate juice and pomegranate nutritional supplements contained antioxidants that delivered unique health benefits. A famous advertisement for their pomegranate juice showed a bottle of juice with a noose around its neck and the slogan "cheat death." POM sponsored some scientific research that demonstrated certain health functionalities of their products, but most of the findings were much more limited in scope than the advertisements would lead a consumer to believe. During trial, a thorough review of POM's sponsored studies was conducted, revealing substantial limitations to the findings and concluding that the products were not capable of treating or preventing disease. The company argued that no reasonable consumer would infer that their products actually treat or prevent disease because the advertisements were lighthearted and humorous; however, federal regulators and the courts took a different view. The judge found that a reasonable consumer would interpret the advertisements as a claim that the POM products would treat, prevent, or reduce the risk of certain diseases. The case ended with the delivery of a 20-year injunction against POM, its officers, and parent company for making false and unsubstantiated health claims for its products.

Interestingly, the FTC had maintained in this case that food and dietary supplement manufacturers should conduct randomized clinical trials for their products in a fashion similar to what the U.S. Food and Drug Administration (FDA) requires for drug com- panies if their products are being promoted for prevention or treatment of disease. However, the judge found that foods and supplements should be treated differently than drugs because most foods and supplements are generally safe and have limited side effects. Because this ruling displeased the FTC, the FTC also appealed the judge's ruling, leading to a reconsideration of the case by the FTC. In Jan. 2013, The FTC made its ruling, which rejected the administrative law judge's position regarding randomized clinical trials. In their ruling, they agreed with the original assertions of the FTC that POM should be required to present two randomized clinical trials to substantiate claims regarding heart disease, prostate cancer, and erectile dysfunction (Villafranco and Pippins, 2013). This ruling may foreshadow an expansion of clinical trial experiments for future health claims for food products. The ruling focused on claims made for treatment, prevention, or reduction of risk for serious diseases but does not cover general health benefit claims. The critical issue here is the definition of the phrase "serious diseases," of which heart disease and prostate cancer are a part. Another interesting aspect of this case was an assessment of qualifiers such as "may," "preliminary," or "promising" on health claims for food products. The FTC found that these qualifiers failed to limit the overall impression that the advertisements were claiming clinical proof, in part because the qualifiers were often part of statements in which a medical symbol such as a caduceus or claim of the amount of money spent on studies accompanied the text (Villafranco and Pippins, 2013).

The administrative law judge in the POM appeal had written that clinical trials on food and supplements were difficult to conduct for a number of reasons and were in addition difficult to pay for because there is often no way to capture intellectual property protection or patent protection on a food. These are indeed two of the reasons why clinical trials for food and food products have been limited in frequency. Instead, the judge indicated that food and nutritional supplement manufacturers should be able to produce competent and reliable scientific evidence to support health claims. The degree to which such evidence is considered competent and reliable will most likely fall to specific experts in the field. The FTC had also requested that POM obtain preapproval from the FDA for any health prevention or disease treatment claim, a request that was denied by the court but that continues to be a practice of the FTC with companies who have been found to make health claims that are unsubstantiated.

Although distinct from vegetables, recent claims made for cereals suggest how certain food-based health claims are viewed by federal regulators. General Mills, maker of breakfast cereals and other processed food products, has made a health claim on its Cheerios product that consumers can lower their cholesterol $4 \%$ in 6 weeks by consuming the product. The claim was based on a study conducted by Provident Clinical Research, who found that eating two 1.5-cup servings of Cheerios daily, as part of a reduced-calorie diet low in fat, lowered lowdensity lipoprotein cholesterol $\approx 10 \%$ in 1 month. When the FDA raised its initial concern about the statement on the box in 2009, General Mills removed the claim and replaced it with the statement that Cheerios "may help reduce your cholesterol." The FDA found that the indication a product was "clinically proven to help lower cholesterol" made the product a drug under federal law and found that it should be regulated as such. The FDA concluded that Cheerios was misbranded because it bore unauthorized health claims in its labeling (FDA, 2009). This in turn led to a class action lawsuit by consumers who claimed they were misled by General Mills into buying a product that lacked the characteristics they believe they had purchased. Kellogg's, another major manufacturer of breakfast cereals, also agreed to pay $\$ 5$ million to settle a lawsuit concerning its mislabeling cereal boxes for a claim focusing on supporting immunity in children.

\section{CLINICAL TRIALS: POSSIBILITIES AND PITFALLS}

A clinical trial is an experiment designed to test the efficacy of a particular product, often a drug, medical device, or therapeutic protocol, through a rigorous evaluation. Clinical trials are often viewed as definitive evidence by practitioners and can be used to direct medical practice. Several types of clinical trials are commonly used, including interventional studies, in which research subjects are given a particular drug or other treatment and are compared with subjects who do not receive the treatment or observational studies, in which the researchers observe a set of subjects and evaluate their outcomes. In an observational study, researchers are evaluating correlations between treatments and health outcomes. In a randomized controlled trial that might be typical for an interventional study, a subject would be randomly assigned to a group to either receive the treatment or a placebo. Often, the subjects are blinded such that they do not know which treatment they are receiving. A double-blind study means that the researchers themselves do not know which treatment is being given to any particular subject, and it may have the effect of reducing bias during the experiment. Finally, many of these studies are also placebo-controlled, meaning that one of the treatments is fake, allowing the investigators to examine the effect of the treatment from any effect caused by the study itself. Clinical trials are expensive and timeconsuming, and many of their aspects are regulated, from the recruitment of human subjects by Institutional Review Boards to a review of the protocol by federal agencies such as the FDA.

As might be expected, it is difficult to conduct clinical trials in which the primary treatments are food. Although it may be 
possible to recruit human subjects and to assign them randomly to groups, the possibility of blinding the subjects or investigators to a particular treatment is often extremely difficult given the sensory nature of most foods. In addition, it is nearly impossible to construct reasonable placebos for most foods. In the case of garlic and onion described previously, it is hard to imagine what would constitute a reasonable placebo for these foods given their aromatic nature and pungent flavors. Although the outcome of the POM case demonstrates that clinical trials are not necessary to make health claims for food and food products, such trials still represent one of the most well-respected and cited methods for producing convincing scientific findings that influence both medical practice and public policy. Even for foods that can be evaluated in this manner, cost may be prohibitive because many basic commodities cannot be protected through patents or other forms of intellectual property licensing; therefore, it is difficult to recoup the extensive costs associated with such trials. It is more likely that future health claims for fruits and vegetables will be produced through scientific studies in which the focus will be on amassing competent and reliable evidence that can be evaluated and substantiated by experts in the field. One piece that should be mentioned is the existence of large-scale cohort studies such as the Nurse's Health Study and Health Professionals Follow-up Study, conducted by scientists at Harvard Medical School (Hung et al., 2004). Studies like these follow more than 100,000 subjects for many years, examining food intake including fruit and vegetable consumption. Data from studies like these focus on the number of servings of fruits and vegetables as well as the types of fruits and vegetables consumed, but they do not generally provide data that are specific to individual crops and their specific health outcomes. Despite this lack of granularity with respect to individual foods and their health outcomes, the studies provide a wealth of clinically relevant information on fruit and vegetable consumption patterns and their effects.

\section{BREEDING AND ANALYSIS OF HEALTH FUNCTIONAL COMPOUNDS}

There has been a steady rise in the amount of research and development aimed at understanding and improving the phytonutrient content of vegetable crops (NewellMcGloughlin, 2008). For the purpose of this article, a phytonutrient may be defined as a plant-based compound that has not been formally designated as a nutrient but nevertheless possesses health-related bioactivity. Although recognition and awareness of potentially healthfunctional compounds may have increased during the past 15 years, much remains to be learned concerning the long-term value of phytonutrients in the context of a complex modern human diet. Some consumers express their concern that the reported efficacy for a particular food or ingredient is often later contradicted by further studies. Despite our lack of understanding of the specific relationships between food and health outcomes, and often without substantial preliminary data, many efforts have been made to enhance the concentration or quality of suspected healthpromoting substances in crop plants (NewellMcGloughlin, 2008).

Plant breeders have been successful in increasing the kinds and amounts of specific, putative health-functional constituents in crop plants as well as decreasing certain antinutritional factors. These include increases in carotenoids in carrot (Daucus carota) (Simon and Goldman, 2007), increases in beta carotene in tomato (Lycopersicon esculentum) (Stommel, 2001), increases in lycopene in tomato (Foolad, 2013) and watermelon (Citrullus lunatus) (Perkins-Veazie and Davis, 2004), increases in certain glucosinolates in vegetable Brassica crops (Sarikamis et al., 2006), increases in betalains in table beet (Beta vulgaris) (Gaertner and Goldman, 2005), and decreases in oxalates in plants (Nakata, 2003) to name a few. In addition, variability and putative health functionality of these compounds have been measured in planta, in in vitro laboratory studies (e.g., Tadmor et al., 2005), in certain in vivo studies with humans and animals (e.g., Tsitsimpikou et al., 2013), and in ex vivo investigations using blood or tissue derived from human or animal subjects after an intervention (e.g., Briggs et al., 2001; Garcia-Alonso et al., 2012). For certain compounds, bioavailability has been measured and the effects of processing have been evaluated (e.g., Etcheverry et al., 2012). Some putative health functionalities such as onion-induced antiplatelet activity in onion have been evaluated for changes during the postharvest period (Debaene et al., 1999) or the way in which they are influenced by various agricultural practices (Orvis et al., 2001). In certain cases, genes influencing the composition and amount of these compounds have been identified (Gasper et al., 2005), and in a number of cases, both traditional breeding and transformation have been used experimentally to augment their levels (Sarikamis et al., 2006). Several germplasm releases have resulted from these efforts, including high lycopene tomatoes (Foolad, 2013).

The health functionality of these compounds is often not well established beyond preliminary investigations such as those described here. Although it is not uncommon to find examples of positive health functionality of plant-based compounds in the scientific literature, substantial questions regarding how such foods and food products would behave in the context of a complex human diet remain to be answered. Breeding activities for these compounds will likely continue and collaborations between breeders and food chemists as well as among medical scientists will continue to reveal where such health-functional compounds can play the most significant role. However, it remains challenging to include food and food products in randomized clinical trials to the extent that synthetic drugs have been included because of the limitations noted.

\section{OTHER CONSIDERATIONS: MARKETING, PLANT BIOLOGY, AND NUTRIGENOMICS}

Given the complexity of the regulatory landscape, new efforts have started to promote basic horticultural commodities without making health claims. One such effort began in 2010, when a group of carrot growers in the United States announced their collaboration on a \$25 million marketing campaign to promote baby carrots as junk food. The campaign attempts to break into the $\$ 18$ billion snack food industry by "Taking a page out of junk food's playbook and applying it to baby carrots" (Horovitz, 2010). Motts has also recently introduced products such as apple juice that include "hidden" or masked vegetable servings in an attempt to provide vegetable-based nutrition without promoting it as such. At the same time, consumer interest in whole foods with enhanced nutritional qualities is at an all time high with more and more consumers making food choices based on suspected health functionality and efforts directed toward labeling for health functionality (Cappellano, 2009). These efforts are accompanied by an increasing emphasis on locally sourced vegetables, farmers' markets, and sustainable farming practices (Clifford, 2010) with emphasis on improved health value for the consumer and the environment in which the food is grown.

Another avenue for agricultural commodities with potential health functionality is for their sale as nutritional supplements. Nutritional supplements are regulated differently than foods or drugs and are largely controlled by the Dietary Supplement Health and Education Act of 1994, known as DSHEA. Nutritional supplements are products intended to supplement the diet that may have ingredients such as minerals, botanicals, amino acids, vitamins, and the like. The FDA has been given the authority to regulate their labeling and manufacturing practices. Manufacturers of dietary supplements may add claims to their labels that describe the putative effect of the product. Garlic and onion are but two examples of foods that can be purchased as basic agricultural commodities and also as nutritional supplements. Often, the supplements are dried or otherwise extracted and in some cases some proprietary blend is sold that combines multiple plants in the product. Claims found on garlic preparations sold as nutritional supplements may include the promotion of cardiovascular health, the possession of antioxidant activity, and cholesterol maintenance.

Vegetable Alliums including onion, garlic, leek, and chive have numerous health-related properties that have received substantial study (Block, 2010). They are also among the most ancient vegetable crops associated with medicinal properties. It has been understood for some time that particular health-functional traits in these vegetables are correlated with the concentration of organosulfur compounds. The functionality of these compounds is based on their activity (Goldman et al., 1996); 
however, many vegetable Alliums also contain fructans and various anthocyanins that may deliver health functionality as well. Because organosulfur compounds are associated with pungency, increasing the medicinal activity of these vegetables can translate into increased pungency for the consumer. This in turn poses a dilemma for consumers because increased pungency necessitates cooking to render onions and garlic palatable. Numerous studies have demonstrated that cooking and heating reduce or destroy in vitro health-related properties such as the ability of these vegetables to inhibit platelet aggregation (Chen et al., 2000; Hansen et al., 2012). Thus, significant attempts have been made to breed onion for lower amounts of pungency and associated organosulfur compounds so that the vegetables can be more palatable and desirable in raw form. This, then, represents the irony of a breeding approach designed to reduce the health functionality of a vegetable crop so that health-functional compounds can be delivered to the consumer.

McCallum et al. (2007) have identified a major quantitative trait locus for bulb pungency and sulfur assimilation in onion that may facilitate selection and breeding. Recently, several new lower-pungency storage onions have been developed that may offer improved health benefits as a result of their palatability as uncooked vegetables. This example illustrates that simply maximizing health-functional compounds may not be the ultimate goal of plant breeders. Instead, plant breeders must focus on the bioavailability of health-functional components as they actually appear in the diet. It is therefore critical that breeders work in interdisciplinary teams with nutritional scientists and food scientists to assess bioavailability and make sure it is in concert with breeding goals. It is also important to be reminded that increasing defensive compounds to levels that have great benefit for pest resistance may also result in these crops being resistant to human interest as well.

The consumption of broccoli and other vegetables from the family Brassicaceae has long been linked to lower cancer risk. A number of epidemiological studies in Asia, the United States, and Europe suggest that risk of lung, breast, colon, and prostate cancer may be reduced with consumption of vegetables from the Brassicaceae (Juge et al., 2007). The suspected mechanism for this risk reduction is the action of isothiocyanates sulforaphane (SF) and iberin. These are derived from glucosinolates found in broccoli florets, which are transformed into isothiocyanates by the action of the enzyme myrosinase in a transformation similar to that which occurs in vegetable Alliums by the enzyme alliinase. Initially, SF was thought to induce protective (Phase II) enzymes, which have detoxification capabilities. However, it is not clear how much of the potential anticarcinogenic activity of SF is the result of Phase II enzyme induction, and there is some evidence that SF can induce apoptosis.

Mithen and coworkers have developed high glucosinolate broccoli germplasm (Sarikamis et al., 2006) using introgressions from a wild species, Brassica villosa. They found that $B$. villosa alleles were responsible for whether iberin or SF is generated on hydrolysis and point to the possibility that broccoli with elevated glucosinolate levels may be a suitable delivery system for SF in the human diet.

The degree to which vegetable Brassicas are protective against cancer is likely also the result of the genotype of the consumer at the GSTM1 locus, leading to the importance of a new field known as nutrigenomics in understanding the full picture of the relationship between food and health. (Juge et al., 2007). The GSTM1 locus is responsible for producing the enzyme glutathione transferase, which catalyzes the conjugation of glutathione with isothiocyanates. It appears that $\approx 50 \%$ of the human population carries a deletion of the GSTM1 gene (Juge et al., 2007), thereby reducing their ability to conjugate, process, and excrete isothiocyanates. Those individuals possessing one or two alleles at GSTM1 may possess greater cancer protection than those who are null for these alleles because the isothiocyanates are retained in their system before excretion. Perhaps the increased retention time for these isothiocyanates increases the chance that they will be able to confer healthbeneficial effects. Individuals who are null for this allele would likely have their SF absorbed, conjugated to glutathione, and excreted through the mercapturic pathway.

Adding to the complexity of this situation is the fact that the predominant vegetable Brassica in Asia is Chinese cabbage from the species Brasscia rapa instead of Brassica oleracea. In the case of Brassica rapa, different isothiocyanates are present, and evidence suggests that the reverse is true, namely that those individuals who are null for GSTM1 gain an additional protective benefit (Gasper et al., 2005). This example illustrates another aspect of complexity in breeding for health functionality in vegetable crops. Human genetic variability has not generally been considered in the context of breeding programs, but it may have significant implications for the finished cultivar or germplasm. Thus, when breeding targets are established, it may be important to explore the extent to which human variability and resulting bioavailability influence health outcomes for the particular commodity.

\section{CONCLUSION}

Increases in health functionality of vegetable crops through breeding should result in food products that deliver more benefits than current versions of these crops. Because many crops were domesticated with specific health properties in mind, it is likely that these crops will continue to have impacts on human health. Some of the compounds that deliver health functionality have been well documented and a few have received some study beyond simple in vitro laboratory investigations. Many of these compounds have been shown to vary with cooking, processing, and certain agricultural practices, making the health-functionality picture even more multifaceted. We also lack substantial clinical trial data for most of these foods and are unlikely to fill that gap because of the complexities involved in such trials. Although randomized clinical trials are considered the best form of information on dietary or health interventions, they are not necessarily required for making a health claim for a food. Instead, substantial competent and reliable evidence that has been produced through objective means is needed. Marketing efforts have, to some extent, overstepped their bounds with respect to the documentation on these foods preventing, treating, or curing serious diseases, but government regulators and other bodies have begun weighing in on these claims and are taking a closer look at what can legally be promoted and what must be avoided. Many of the health benefits of these foods will likely be determined in this way, through the accumulation of substantial evidence over time, rather than through very large randomized clinical trials.

The health functionality of many agricultural commodities is an excellent avenue for future study. Despite at least two decades of increasing research, many questions remain to be sorted and addressed. Interestingly, the consumption of fruits and vegetables for their own sake has often been shown to be protective against certain serious diseases in clinical trials. It has primarily been in studies designed to examine very specific nutrients or compounds found in those foods that their relationship to health functionality has become murkier. Perhaps future progress in human health may be associated with the consumer's interest in fruit and vegetable consumption for its own sake as a lifestyle and a practice, rather than as a prescriptive solution to medical problems.

\section{Literature Cited}

American Dietetics Association. 2009. Position of the American Dietetic Association: Functional foods. 2009. J. Amer. Diet. Assoc. 109:735-746. Andon, M.B., M. Peacock, R.L. Kanerva, and J.A. De Castro. 1996. Calcium absorption from apple and orange juice fortified with calcium citrate malate (CCM). J. Amer. Coll. Nutr. 15:313-316

Bellavia, A., S.C. Larsson, M. Bottai, A. Wolk, and N. Orsini. 2013. Fruit and vegetable consumption and all-cause mortality: A dose-response analysis. Amer. J. Clin. Nutr. 98:454-459.

Block, E. 2010. Garlic and other alliums: The lore and the science. RSC Publishers, Cambridge, UK.

Briggs, W.H., J.D. Folts, H.E. Osman, and I.L. Goldman. 2001. Administration of raw onion inhibits platelet-mediated thrombosis in dogs. J. Nutr. 131:2619-2622.

Cappellano, K. 2009. Influencing food choices: Nutrition labeling, health claims, and front-ofthe-package labeling. Nutr. Today 44:269-273.

Charradi, K., S. Elhahoui, I. Karkouch, F. Limam, G. Hamdaoui, F.B. Hassine, M. Veronique El May, A. El May, and E. Aouani. 2013. Grape seed and skin extract alleviates high-fat dietinduced renal lipotoxicity and prevents copper depletion in rat. Appl. Physiol. Nutr. Metab. 38:259-267. 
Chen, J-H., H-ing Chen, T. S-Jen, and C. Jen. 2000. Chronic consumption of raw but not boiled Welsh onion juice inhibits rat platelet function. J. Nutr. 130:34-37.

Clifford, S. 2010. Wal-Mart to buy more local produce, p. B1. New York Times. 14 Oct.

Debaene, J.E.P., I.L. Goldman, and B.S. Yandell. 1999. Postharvest flux and genotype $\times$ environment effects for onion-induced antiplatelet activity, pungency, and soluble solids in long day onion during postharvest cold storage. J. Amer. Soc. Hort. Sci. 124:366-372.

Etcheverry, P., M.A. Grusak, and L.E. Fleige. 2012. Application of in vitro bioaccessibility and bioavailability methods for calcium, carotenoids, folate, iron, magnesium, polyphenols, zinc, and vitamins B(6), B(12), D, and E. Front Physiol. 3:317.

Food and Drug Administration. 2009. U.S. Department of Health and Human Services. $<$ http://www.fda.gov/iceci/enforcementactions/ warningletters/ucm 162943.htm>.

Foolad, M. 2013. High lycopene content tomato plants and markers for use in breeding for same. US Patent 20130074204 A1.

Gaertner, V.L. and I.L. Goldman. 2005. Pigment distribution and total dissolved solids of selected cycles of table beet from a recurrent selection program for increased pigment. J. Amer. Soc. Hort. Sci. 130:424-443.

Garcia-Alonso, F.J., V. Jorge-Vidal, G. Ros, and M.J. Periago. 2012. Effect of consumption of tomato juice enriched with n-3 polyunsaturated fatty acids on the lipid profile, antioxidant biomarker status, and cardiovascular disease risk in healthy women. Eur. J. Nutr. 51:415424.

Gasper, A.V., A. Al-Janobi, J.A. Smith, J.R. Bacon, P. Fortun, C. Atherton, M.A. Taylor, C.J. Hawkey, D.A. Barrett, and R.F. Mithen. 2005. Glutathione S-transferase M1 polymorphism and metabolism of sulforaphane from standard and high-glucosinolate broccoli. Amer. J. Clin. Nutr. 82:1283-1291.

Goldman, I.L. 2003. Recognition of fruits and vegetables as healthy: Vitamins and phytonutrients. HortTechnology 13:252-258.

Goldman, I.L., M. Kopelberg, J.E. Debaene, and B. Schwartz. 1996. Antiplatelet activity in onion (Allium cepa) is sulfur dependent. Thromb. Haemost. 76:450-452.

Hansen, E.A., J.D. Folts, and I.L. Goldman. 2012. Steam-cooking rapidly destroys and reverses onion-induced antiplatelet activity. Nutr. J. 11:76.

Horovitz, B. 2010. Baby carrots take on junk food with hip marketing campaign. USA Today. 3 Sept. 2010. <http://usatoday30.usatoday.com money/industries/food/2010-08-29-baby-carrotsmarketing_N.htm>.

Hung, H.C., K.J. Joshipura, R. Jiang, F.B. Hu, D. Hunter, S.A. Smith-Warner, G.A. Colditz, B. Rosner, D. Spiegelman, and W.C. Willett. 2004. Fruit and vegetable intake and risk of major chronic disease. J. Natl. Cancer Inst 96:1577-1584.

Janick, J. 2003. Herbals: The connection between horticulture and medicine. HortTechnology 13:229-238.

Juge, N., R.F. Mithen, and M. Traka. 2007. Molecular basis for chemoprevention by sulforaphane: A comprehensive review. Cell. Mol. Life Sci. 64:1105-1127.

Lawson, L.D. 1998. Garlic: A review of its medicinal effects and indicated active compounds. In: Lawson, L.D. and R. Bauer (eds.). Phytomedicines of Europe. American Chemical Society Symposium Series 691. American Chemical Society, Washington, DC.

McCallum, J., M. Pither-Joyce, M. Shaw, F. Kenel, S. Davis, R. Butler, J. Scheffer, J. Jakse, and M.J. Havey. 2007. Genetic mapping of sulfur assimilation genes reveals a QTL for onion bulb pungency. Theor. Appl. Genet. 114:815-822.

Meyer, R.S., A.E. DuVal, and H.R. Jensen. 2012. Patterns and processes in crop domestication: An historical review and quantitative analysis of 203 global food crops. New Phytol.

Nakata, P.A. 2003. Advances in our understanding of calcium oxalate crystal formation and function in plants. Plant Sci. 164:901-909.

Newell-McGloughlin, M. 2008. Nutritionally improved agricultural crops. Plant Physiol. 147:939-953.

Nolen, S. 2011. India in a stew over onion shortage. Globe and Mail. 20 Jan. 2011. <http://www. theglobeandmail.com/news/world/india-in-astew-over-onion-shortage/article564283/>.
Orvis, K., P. Barak, and I.L. Goldman. 2001. Excess sulfate supply and onion-induced human antiplatelet activity. J. P1. Nut. Soil Sci. 164:457-462.

Perkins-Veazie, P. and A.R. Davis. 2004. In search of high lycopene watermelon. Cucurbit Genetics Coop. Rpt. 27:51-53.

Pollan, M. 2006. Omnivore's dilemma: A natural history of four meals. The Penguin Press, New York, NY.

Pollan, M. 2008. In defense of food: An eater's manifesto. The Penguin Press, New York, NY.

Rubatzky, V.E. and M. Yamaguchi. 1997. World vegetables. 2nd Ed. Chapman and Hall, New York, NY.

Sarikamis, G., J. Marquez, R. MacCormack, R.N. Bennett, J. Roberts, and R. Mithen. 2006. High glucosinolate broccoli: A delivery system for sulforaphane. Mol. Breed. 18:219-228.

Simon, P.W. and I.L. Goldman. 2007. Carrot, p. 497-516. In: Singh, R.J. (ed.). Genetic resources, chromosome engineering, and crop improvement. CRC Press, Boca Raton, FL.

Smartt, J. and N.W. Simmonds. 1995. Evolution of crop plants. 2nd Ed. Longman Scientific and Technical, New York, NY.

Smith, J. and E. Charter. 2010. Functional food product development. In: Shahidi, F. (ed.). Functional Food Science and Technology series. Wiley Blackwell.

Stommel, J.R. 2001. USDA 97L63, 97L66, and 97L97: Tomato breeding lines with high fruit beta-carotene content. HortScience 36:387-388.

Tadmor, Y., S. King, A. Levi, A. Davis, A. Meir, B. Wasserman, J. Hirschberg, and E. Lewinsohn. 2005. Comparative fruit colouration in watermelon and tomato. Food Res. Intl. 38:837-841.

Tsitsimpikou, C., N. Kioukia-Fougia, K. Tsarouhas, P. Stamatopoulos, E. Rentoukas, A. Koudounakos, P. Papalexis, J. Liesivuori, and A. Jamurtas. 2013. Administration of tomato juice ameliorates lactate dehydrogenase and creatinine kinase responses to anaerobic training. Food Chem. Toxicol. [Epub ahead of print].

Villafranco, J. and R. Pippins. 2013. Health claims check: the case of POM Wonderful. Nutritional Outlook. March. p. 18-19.

World Health Organization. 2004. Fruit and vegetables for health. Report of a joint FAO/WHO workshop, 1-3 Sept., Kobe, Japan. 